\title{
Research on the Presentation
} Methods of MOOCs' Teaching Video Based on the Qualitative Research Approached: A Case Study of 322 National-Level Quality MO0Cs

\author{
Shixiao Wang ${ }^{1}$, Ming Chen'1, Mei Li¹, Yuchen Liu², Xiaoling Ye ${ }^{1^{*}}$ \\ ${ }^{1}$ School of Educational Science, Nanjing Normal University, Nanjing, China \\ ${ }^{2}$ Business School, University of Sydney, Sydney, Australia \\ Email: *yxlheart@126.com
}

How to cite this paper: Wang, S. X., Chen, M., Li, M., Liu, Y. C., \& Ye, X. L. (2021). Research on the Presentation Methods of MOOCs' Teaching Video Based on the Qualitative Research Approached: A Case Study of 322 National-Level Quality MOOCs. Open Journal of Social Sciences, 9, 368-379. https://doi.org/10.4236/jss.2021.910026

Received: September 30, 2021

Accepted: October 26, 2021

Published: October 29, 2021

Copyright $\odot 2021$ by author(s) and Scientific Research Publishing Inc. This work is licensed under the Creative Commons Attribution International License (CC BY 4.0).

http://creativecommons.org/licenses/by/4.0/ c) (i) Open Access

\begin{abstract}
MOOCs, as a new educational mode and form, has been widely welcomed around the world and also flourished in China for nearly ten years. Under the background that China has the largest total amount of MOOCs in the world, it is of great significance to explore the characteristics of high-quality MOOCs presentation mode for the future development. At present, although many studies have proved that the presentation mode of MOOCs' teaching video has an impact on the teaching effect of MOOCs, there are few answers to questions such as "how to present" and "why to present in this way". Based on this, from the perspective of qualitative research, this study selects the "national high-quality online open course", which represents the highest level of online video in China, and analyzes the current online teaching video mode. The study found that in different types of teaching videos, the frequency and location of teacher images are different, and the key points and auxiliary teaching methods of making videos are also different. At the same time, the research also talks with a large number of existing researches in order to provide the construction ideas of high-quality resources for the builders of follow-up MOOCs courses.
\end{abstract}

\section{Keywords}

MOOCs, Teaching Video Presentation, Teachers' Image, Chinese Quality 
Open Course, Qualitative Research

\section{Introduction}

In recent years, Massive Open Online Courses (MOOCs), as a new form and mode of the education, has received lots of attention across the world since its launch. The main reasons behind are its features of high degree of openness, large capacity of learners and miniaturization of teaching videos. After the booming developments in the recent decade, the total amount of Chinese MOOCs has become the first place in the world (Ministry of Education, 2018a). Chinese government highly focuses on online teaching as well as the popularization of MOOCs' constructions. In early 2018, the National Ministry of Education has selected and released the 490 national-level of MOOCs, covering the specialization of arts, science, engineering, agriculture and medicine in all higher education. This is the first batch of establishment of national-level MOOCs in China as well as around the world, which aims to significantly improve the quality of higher education (Ministry of Education, 2018b). With such strong impetus of online education, there are over 40,000 online courses available for learners in China. What should be done to guarantee the quality of those MOOCs has become a thought-provoking question after the outbreak of MOOCs.

As a type of digital resource, the quality of MOOCs video could be affected by quality controls and by how it is presented. In terms of quality control, the national-level MOOCs are strictly selected by the Ministry of Education from aspects of teaching team, contents, conditions, methodologies, effects and features, which represent the highest level of Chinese MOOCs video. In terms of presentation, although many empirical studies had proved that the way of presenting videos has impact on MOOCs' teaching effect, there are few solutions for coping with questions such as "how to present" and "why it should be presented in such a way". Based on such problems, this research will conduct a qualitative analysis on the presentation methods of national-level MOOCs teaching video and their corresponding reasons by intensively researching existing literature studies to provide constructive thinking and ideas with high-quality resources for the subsequent MOOCs constructions.

\section{Literature Review}

With the rapid expansion of MOOCs, high dropout rate, low teaching efficiency and other questions have continuously emerged in recent years and researchers start to focus more on the optimization of MOOCs' quality. Video is the main route of knowledge transmission for teachers so that more and more researchers put considerable interest directly in studying the presentation method of MOOCs itself, other than other features of MOOCs such as its teaching content or methodologies. Researchers compare the influence of different presentation methods of 
MOOCs teaching video on learners from learning effect, cognition and other aspects, which are mainly concentrated in the following aspects:

\subsection{Researches on Classifications of MOOCs' Teaching Video}

Now, there is no consistent definition of MOOCs' presentation methods. This subsequently derives different ways of MOOCs' teaching video categories. For example, Jian Wang et al. (2014) take different combination of video interfaces as basis of classification. Jiumin Yang (2014) divided the MOOCs' teaching video into teacher fusion type, teacher embedded type and class recording type, based on whether there are appearances of teachers' image or not. Qingqing Yu \& Xiaoming Li (2015) classify the MOOCs' teaching video according to their production methods. From the perspective of knowledge categories, Shenghua Yang (2017) divided the MOOCs' teaching micro video as handwriting type, live-shooting type, courseware animation type, combination of teaching and PowerPoint type and interaction type.

\subsection{Researches on the Presentation Methods of Teachers' Images in MOOCs' Teaching Videos}

Due to the separation of teachers and students in time and location, the lack of emotional communication among them could affect the students' cognition process. The teachers' images have subsequently become a significant factor to be concerned and discussed in MOOCs' teaching micro video (Zheng, 2014). Through the analysis of existing MOOCs, it could be founded that over $90 \%$ of MOOCs have presented the teachers' images in the video. Therefore, more focuses should be put on the presentation methods of teachers' images and roles, such as their gestures and emotional expressions in teaching videos (Sueyoshi \& Hardison, 2005), different size of teachers' figure (Cao et al., 2017), different teachers' images and the relationship between the learning effects and various presentation methods of dynamic and static PowerPoint (Zheng et al., 2012).

\subsection{Researches on the Presentation Methods of Subtitles in M00Cs' Teaching Videos}

Adding subtitles in the MOOCs' teaching videos could whether facilitate the learning progress or not is always debatable at the present stage. Cognitive Theory of Multimedia suggests that the existence of subtitles could result in the redundancy effect that the learners' learning effect would be lowered when accompanied with audio commentaries and subtitles in teaching videos. However, opposite opinions are held by several researchers. For instance, according to Cunyou Wang's study (Wang, 2016), the appearance of subtitles would not generate redundancy effect when the image of video is not important and when the subtitles could be processed automatically by learners at the same time. Also, Sha Sha's study (2017) found that the learners' grade of videos with subtitles are generally better than the grades of videos without subtitles, no matter whether there is a teacher's image in the video or not. 


\section{Research Design}

\subsection{Data Sources}

Chinese quality MOOCs are divided into three construction levels: the school-level, the provincial-level and the national-level MOOCs, among which the national-level MOOCs represent the highest level of Chinese MOOCs at the current stage. During the qualification of the first batch of national-level MOOCs by the Ministry of Education, $69 \%$ of the total number of National-level quality MOOCs was contributed by the MOOCs of domestic universities. Therefore, in order to eliminate the factors from various educational platforms, the data of MOOCs' teaching video of 322 courses in total in this research are all originated from the national-level MOOCs of Chinese domestic universities. Among them, there are 8 courses have been closed so that the video resources of them cannot be accessed. Therefore, the final sample size is 314 courses.

\subsection{Research Methodologies and Tools}

The qualitative research approaches take the researcher himself as the researching tools, adopt diverse collection methods under natural circumstances to comprehensively explore the research problems and then use induction method to analyse the data to subsequently form solutions and theories (Chen, 2008). NVivo11 is a software for data analysis under a qualitative research approach, which is launched by an Australian company namely SQR. It has the advantages of powerful coding function that could be utilized not only for processing textual data such as interview transcript and fieldwork notes, but also for processing non-textual data such as pictures, video and graphs. Hence, NVivo11 would be utilized in this research to transcribe and encode the artificial textual data of 322 samples for analysing the features of their presentation methods and thus conclude several practical rules for the presentation methods of Chinese MOOCs' teaching videos.

\subsection{Research Process}

The encoding in qualitative research approach could be concept-driven or data-driven, where concept-driven encoding method will be adopted in this research. Firstly, on the basis of the existing outcomes of the empirical studies about the presentation methods of Chinese MOOCs' teaching videos, a theme encoding in a top-down manner was conducted. 5 primary case nodes (theme nodes) were generated under such manner, which are the knowledge types of MOOCs' courses, shooting and recording types of MOOCs' teaching video, presentation mode of teachers' images, assistant methods and other presentation methods. Then, more detailed information would be obtained after watching 314 MOOCs' video courses one by one, which would be filed into 314 text documents. The following step is to import those text documents into the "interior materials" of NVivo11 and process a bottom-up analysis coding. Under such manner, forth, tertiary and secondary case nodes would be produced and sorted 
into primary case nodes with corresponding themes. Finally, the structural relationships among nodes are required to be adjusted through reviewing all coding nodes and refining general nodes with continuous comparison and induction. After finalizing the coding process, there are 79 forth case nodes, 56 tertiary case nodes, 19 secondary nodes and 5 theme nodes.

\section{Data Analysis}

Based on the nature and characteristics psychological processing procedure of knowledge acquisition, the psychologist John Robert Anderson (Anderson, 2013) divided the knowledge into two types: declarative knowledge and procedural knowledge. Those two types are the most commonly used knowledge types by researchers. Declarative knowledge is the knowledge of facts, that is, the knowledge of "what is it". The procedural knowledge is the knowledge of the operational action for a specific activity, referring to the knowledge of "how to do". The researcher has followed the Anderson's knowledge type to analyse the features of presentation methods of national-level quality MOOCs' teaching video under different knowledge types, with an adoption of node matrices in NVivo11.

\subsection{Analysis for the Presentation Methods of Teachers' Images}

\subsubsection{The Frequency of Teachers' Images under Different Knowledge Type}

According to the number and types of nodes, the researcher divided the frequency of appearance of teachers' images into three different types as shown in Table 1: always present, intermittent present and no appearance (or few appearance) of teachers' images. In courses with procedural knowledge, the frequency of appearance of teachers' image in a descent order is intermittent present, no appearance and always present. However, in courses with declarative knowledge, such frequency order is intermittent present, always present and no appearance. When watching the video, the researcher found that the courses with declarative knowledge rarely had the situation of no appearance while the courses with procedural knowledge mostly involved the image of demonstration of teachers' calculations and operations. The teachers' image of such courses often appears only before and after the class and the classes were presented in form of PowerPoint's screen recording and commentary.

\subsubsection{The Position and Sizes of Teachers' Images}

For the presentation of position of teachers' images, the researcher collected four tertiary case nodes from the MOOCs' video. The four position nodes are located at left, right, middle and uncertain positions, respectively. Within all courses, the number of teachers' appearance at right position of the video is the highest, accounting for $36.2 \%$ of the total numbers. The following rank is the middle positions and the number of left positions is the lowest with a proportion of $13.4 \%$, as present in Figure 1. 
Table 1. Categories of appearance of teachers' images.

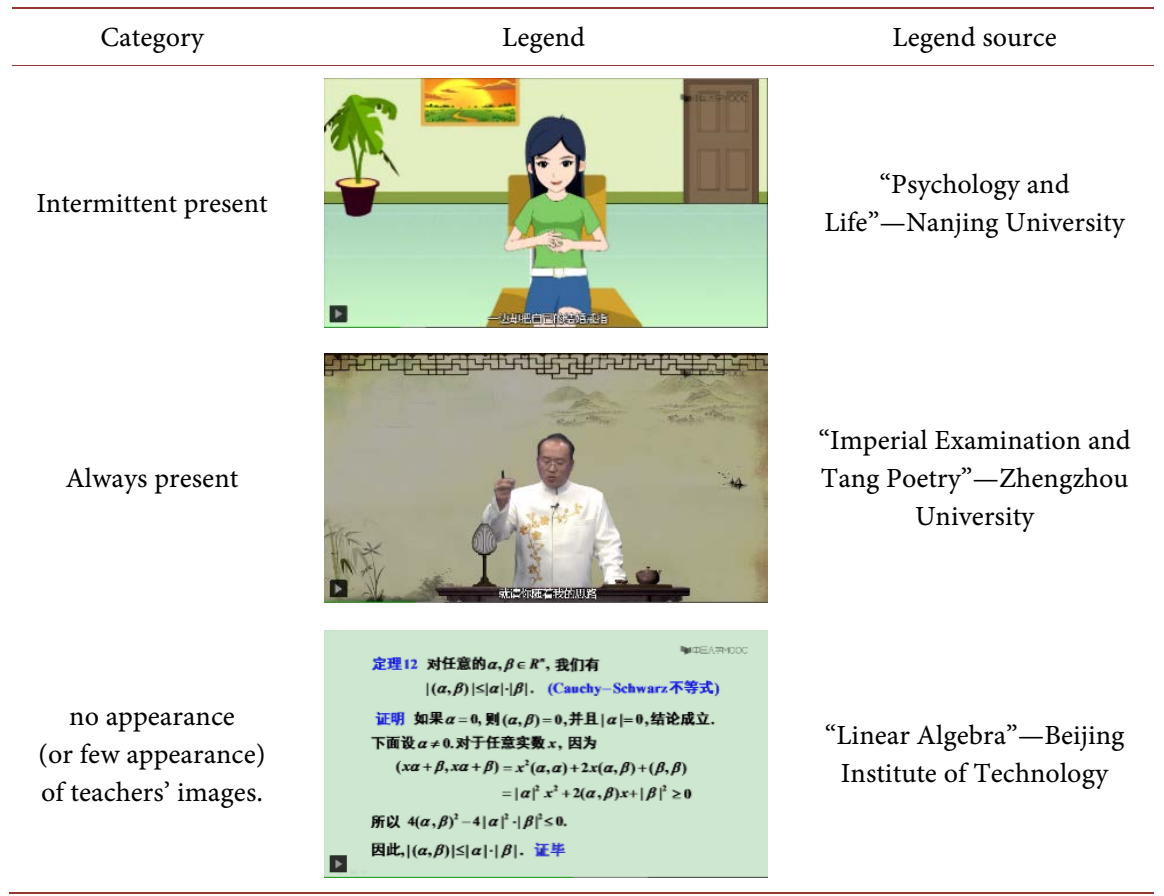

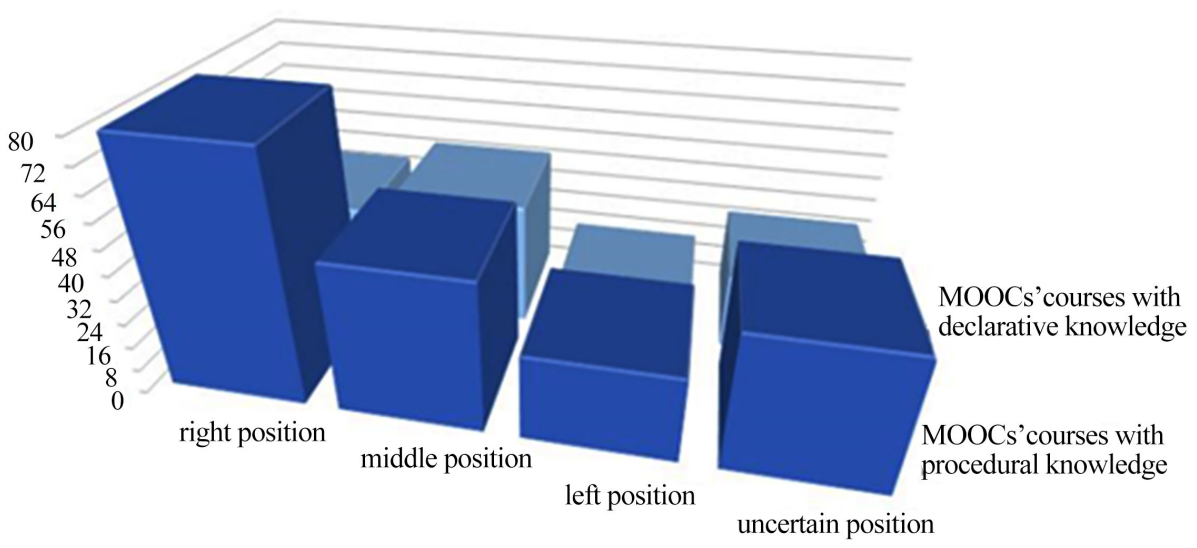

Figure 1. The knowledge type of MOOCs' video courses and the presentation methods of positions of teachers' images.

The size of teachers' image in MOOCs' teaching video is very diverse. As can be seen from Figure 2, the teachers' image size can be ranged from 1/30 to 1/2 of the screen. However, the sizes of teachers' image are mainly concentrated in three categories for both procedural and declarative knowledge courses: the first size is the $1 / 4$ of the screen with the number of 63 and 29 courses respectively; the second size is the $1 / 3$ of the screen with the number of 57 and 41 respectively and the third size is switchable with the number of 40 and 28 respectively. The third category of teachers' image size tends to be general size as extreme large size of teachers' images would be too abrupt and hence affect the complete presentation of course contents while extreme small size would make learners unable to see teachers' facial expression clearly. 


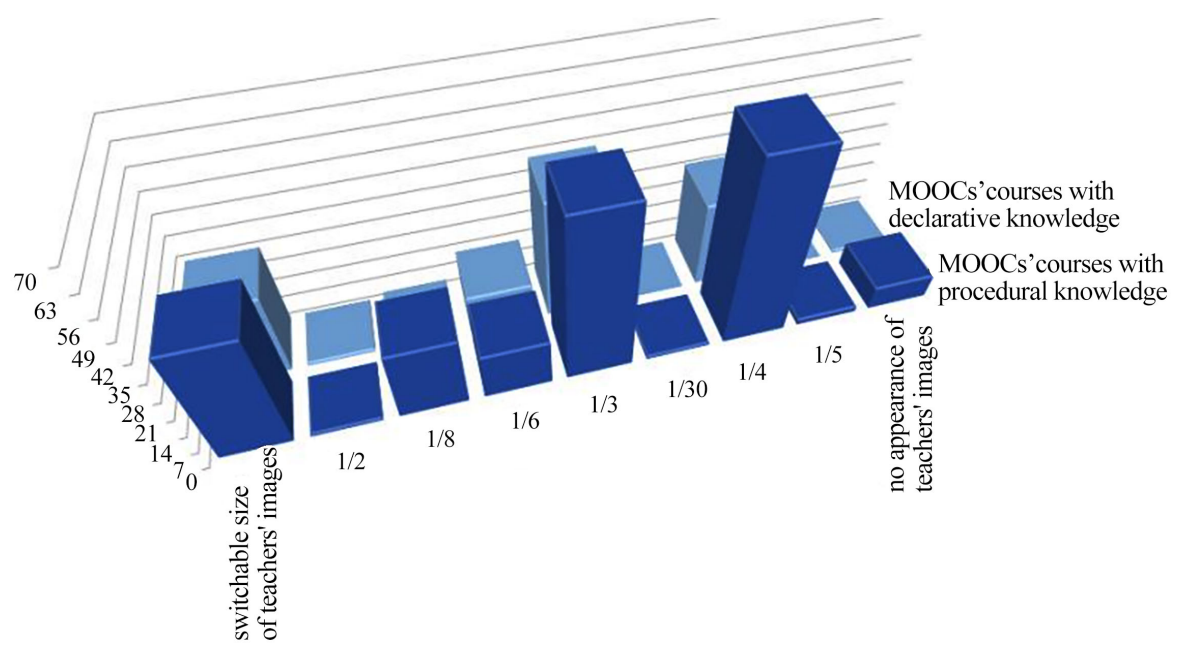

Figure 2. Knowledge types courses in MOOCs' teaching video and the presentation methods of size of teachers' images.

\subsection{Analysis for the Presentation Modes of Assistant Teaching Methods}

\subsubsection{Matrix Analysis of Subtitles and Commentaries}

After watching 314 national-level MOOCs' teaching video, the researcher found that the assistant teaching methods in the courses can be classified as subtitles, commentaries and other assistant teaching methods that include videos, animations and manual card placement. For better exploring the features of these assistant teaching methods as well as the differences of these assistant teaching methods on courses with various knowledge types, the researcher conducts matrices analysis for the corresponding nodes. The results of which are shown in Figure 3.

The result shows that, compared to the courses with declarative knowledge, more subtitles, commentaries and other assistant teaching methods are used in the course with procedural knowledge. As shown in Table 2, the application of subtitles has the largest proportion, where $86 \%$ of courses have used subtitles in their teaching videos, including full subtitles and intermittent subtitles. The next is the application of commentaries, including underlines for key words and highlights for key points with red circles etc. Additionally, more commentaries and notes are used in courses with procedural knowledge than the one with declarative knowledge.

\subsubsection{The Types and Characteristics of Other Assistant Teaching} Methods

Apart from common assistant teaching methods like subtitles and commentaries, it is found that some quality MOOCs' videos have utilized other assistant methods, mainly including the animation demonstration, video demonstration and manual card placement by teachers. The animation demonstration is more often applied in courses with procedural knowledge than in courses with declarative knowledge. Moreover, no matter which knowledge type the courses belongs to, the utilization of video assistant method has highest proportion, followed by the animation demonstration methods. 
Table 2. Categories of assistant teaching methods.

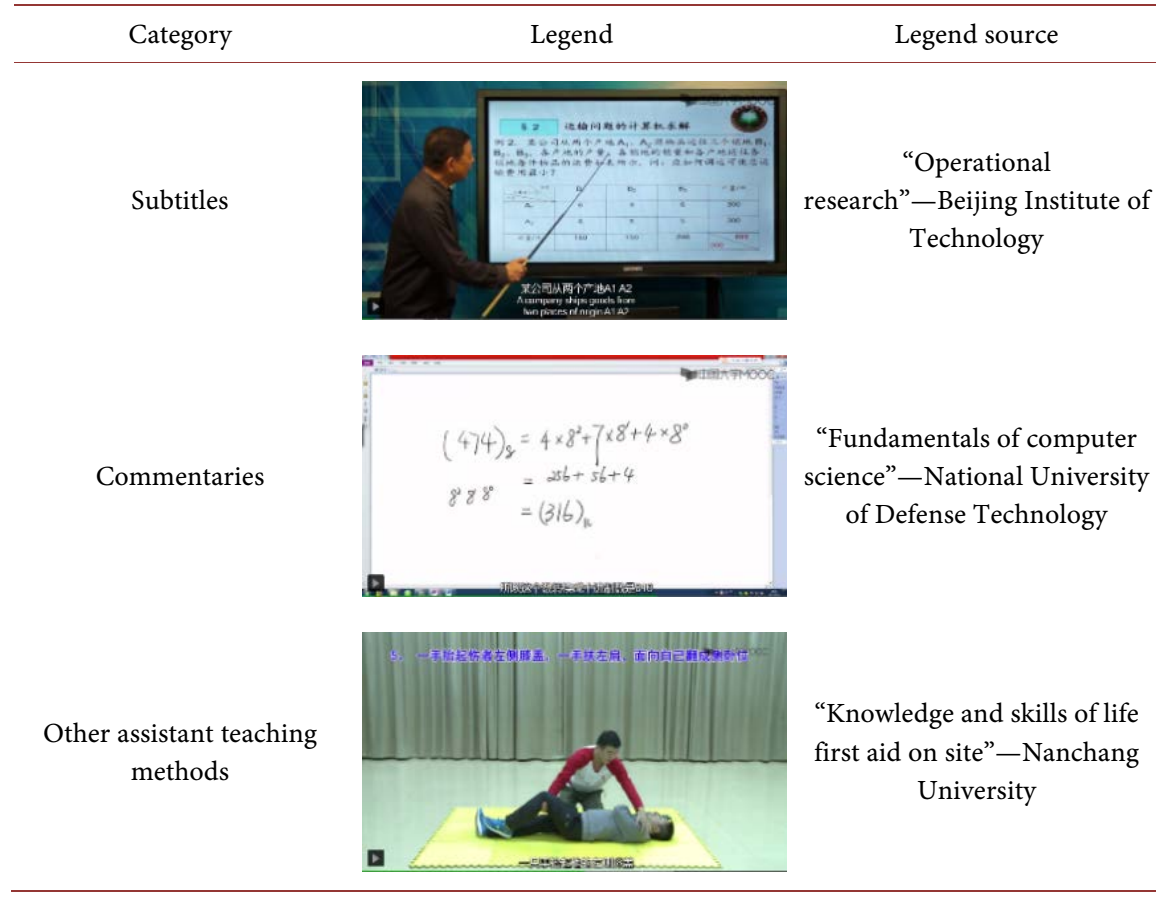

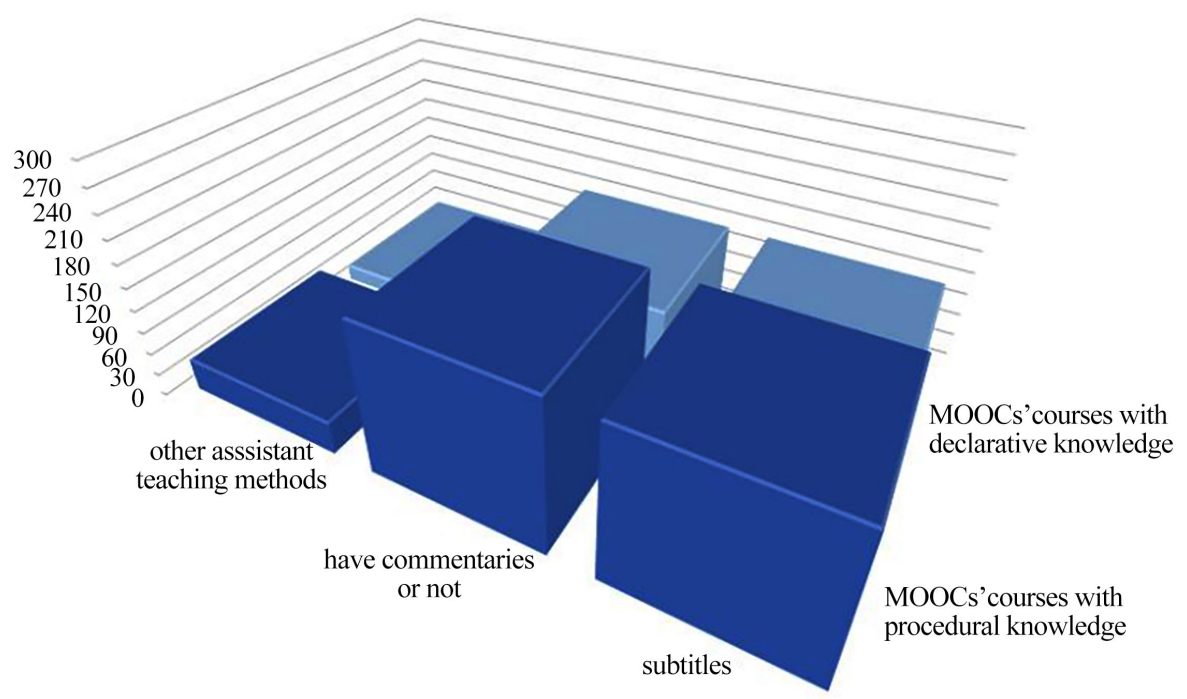

Figure 3. Knowledge types courses in MOOCs' teaching video and the presentation modes of assistant teaching methods.

\section{Findings and Discussions}

The original data of this study are all from the 322 MOOCs in Chinese universities that have won the title of "National Excellent Courses".

On the whole, these videos represent the high level of the current Online open courses in China. According to the qualitative research method and the coding statistics in the data analysis software NVivo11, it is found that these exquisite courses reflect the characteristics of the presentation mode of high-quality teaching videos in the following aspects: 


\subsection{Teachers' Images Appear in Different Types of MO0Cs Videos at Different Frequencies}

Through the analysis of 314 National-level MOOCs, the research founds that the appearance frequency of teachers' images in a descending order for courses with procedural knowledge is: intermittent present, no appearance of teachers' images and always present. For the courses with declarative knowledge, such frequency order is: intermittent present, always present and no appearance.

At the current stage, many researchers conducted comparative analysis for studying the impact of different appearance frequency of teachers' images in teaching videos on learners' learning effect, but conclusions are not consistent (Wang et al., 2018; Kizilcec \& Cohen, 2017). This research found that the "intermittent present" type of appearance of teachers' image has the highest frequency in MOOCs' teaching videos with both knowledge types. However, the "no appearance" and "always present" type of appearance frequency of teachers' images are not the same in order for courses with declarative and procedural knowledge. In procedural knowledge courses, the proportion of no appearance of teachers' image accounts for $15 \%$ of the total numbers while such proportion only contributes a little when comes to declarative knowledge courses. Relatively speaking, declarative knowledge is easier to be characterized than procedural knowledge. Since declarative knowledge more focused on memorization and understanding of the knowledge, the appearance of teachers' images could help learners to feel kindness and supervision from teachers and then focus on teachers' explanation so that their abilities of improving attentions could be enhanced to a certain extent. When learning the procedural knowledge that more focus on the practical operation and process and more rely on learners' operations and connections in later stage, whether teachers' images appear or not will not have significant impact on learners.

\subsection{Teachers' Images Appear in Different Types of M00Cs Videos at Different Locations}

In MOOCs' teaching videos, the number of teachers' images that is located on the right-hand side is the highest, followed by the distribution of middle size, switchable side and left-hand side. The majority presentation of teachers' images tends to be knee shot. When the teachers' "appearances" is on the right-hand side, he/she should be standing on the left-hand side in actual shooting scene. It is more convenient for teachers to point out the key contents on the PowerPoint and hence to make learners' pay more attention to those contents. Such arrangement is consistent with the teachers' actual standing position in traditional classrooms, which is much easier for teachers to film the videos and for students to accept subjectively. However, the current researchers hold different opinions on the relationships of the presentation methods of teachers' images and the learners' learning effects (Yan, 2017; Xu, 2019). The possible reason to explain such fact is that most of existing studies are based on the Cognitive Load Theory 
and Cognitive Theory of Multimedia Learning that focuses on traditional multimedia learning. However, there still are some differences between traditional multimedia learning and MOOCs' video learning, so a more cautious attitude should be held when comes to whether those two theories can be directly applied to the analysis of MOOCs' teaching video or not. In future studies, based on the features of online studying, it is necessary to confront the current situation of MOOCs' teaching in practice so that theories for MOOCs' video learning could be developed to better support and improve the MOOCs and hence to form a virtuous circle.

\subsection{The Emphasis of MOOCs Videos of Different Types of Knowledge Is Different}

It is found that subtitling and annotation have become common teaching AIDS. For example, when the course is annotated, teachers usually underline the corresponding words when explaining the key content. Or when it comes to calculation problems, the teacher will speak and write the calculation process on one side of the screen.

When making the teaching video, therefore, for the selection of auxiliary teaching means according to the content of courses and human time under the consideration of the actual situation such subtitles in design, in addition to being able to present the subtitles at the bottom of the word for word can also add subtitles or rendering only keywords, can reduce the difficulty of the course, let learners better understand the course content.

In the past teaching process, two-channel presentation is considered to be more effective. In fact, in current MOOCs, teaching resources tend to be diversified. This may be because the previous studies were carried out in the ideal environment of the laboratory, and the results obtained are difficult to be promoted in practical teaching, leading to the conclusions of experimental studies inconsistent with the actual situation of MOOCs teaching.

In addition, no matter in existing research or actual teaching, the occurrence frequency of animation AIDS is the lowest, which may be related to the high cognitive load of animation itself. When learners are faced with interesting but short animation learning materials, they will have higher external cognitive load, resulting in poor learning effect.

\section{Research Recommendations}

The conclusion of this research shows that the type of knowledge, teachers' images, and assistant teaching methods in the teaching process are all the directions that high-quality MOOCs courses would focus on. In the future, teachers can improve the quality of courses through the following aspects: 1) Teachers can first plan and sort out the knowledge types of the course. If there is a lot of declarative knowledge, teachers should appear in the video as much as possible;

2) Teachers' images on the right side are more convenient for students to watch, 
thus improving the appreciation of the course; 3) Clever use of the assistant teaching methods can effectively improve the teaching effect, such as subtitles, commentaries, etc. At the same time, it should be known that animation may not have a good effect.

\section{Funding}

This study was supported by the Jiangsu Provincial Superior Discipline Construction Project (PAPD).

\section{Conflicts of Interest}

The authors declare no conflicts of interest regarding the publication of this paper.

\section{References}

Anderson, J. R. (2013). The Architecture of Cognition. Harvard University Press.

Cao, J., Fu, A., Wang, R., Zhou, L., \& Huang, L. (2017). The Influence of Teachers' Presentation in Teaching Videos on Learners' Social Presence and Learning Effects. Modern Educational Technology, No. 7, 75-81.

Chen, X. (2008). The New Development of Qualitative Research and Its Significance to Social Science Research. Educational Research and Experiment, No. 2, 14-18.

Kizilcec, R. F., \& Cohen, G. L. (2017). Eight-Minute Self-Regulation Intervention Raises Educational Attainment at Scale in Individualist but Not Collectivist Cultures. Proceedings of the National Academy of Sciences of the United States of America, 114, 4348-4353. https://doi.org/10.1073/pnas.1611898114

Ministry of Education, People's Republic of China (2018a). The Number of Online Open Courses Has Reached 5,000, Ranking the First in the World. http://www.moe.gov.cn/jyb xwfb/xw zt/moe 357/jyzt 2018n/2018 zt01/zt1801 gxjy/ 201804/t20180424 334036.html

Ministry of Education, People's Republic of China (2018b, January 16). Ministry of Education Promotes the First Batch of 490 "National Quality Online Open Courses". http://www.moe.gov.cn/jyb xwfb/s5147/201801/t20180116 324675.html

Sha, S. (2017). The Impact of Teacher Image and Subtitles in Teaching Micro-Videos on Learning. Master's Thesis, Tianjin Normal University.

Sueyoshi, A., \& Hardison, D. M. (2005). The Role of Gestures and Facial Cues in Second Language Listening Comprehension. Language Learning, 55, 661-699. https://doi.org/10.1111/j.0023-8333.2005.00320.x

Wang, C. (2016). Is It Necessary for the Online Teaching Video to Present and Explain Subtitles? -Also on the Revision of the Boundary Conditions of the Redundancy Effect. Audio-Visual Education Research, No. 3, 59-65+85.

Wang, H., Hu, W., Pi, Z., Ge, W., Xu, Y., Fan, X., \& Liang, Y. (2018). Eye Movement Research on the Influence of Teacher Behavior on the Learning Effect of Instructional Videos. Journal of Distance Education, No. 5, 103-112.

Wang, J., Hao, Y., \& Lu, J. (2014). Teaching Video Presentation the Experimental Study of Effect of Autonomous Learning. Electrochemical Education Research, No. 3, 93-99+105.

$\mathrm{Xu}$, P. (2019). Research on the Effect of Teacher Presentation Based on Eye Tracking 
Technology on MOOC Video Teaching Effects. Master's Thesis, Minzu University of China.

Yan, C. (2017). Experimental Research on the Influence of Teacher Role Presentation in Micro-Classes on Learning Effects. Master's Thesis, Tianjin Normal University.

Yang, J. (2014). The Influence of Teachers on the Learning Process and Effect in Online Video Courses. PhD Dissertation, Central China Normal University.

Yang, S. (2017). Research on the Presentation of Teaching Micro-Videos from the Perspective of Knowledge Classification. Science Education Journal (Mid-Day Issue), No. 1, 43-44

Yu, Q., \& Li, X. (2015). Exploration and Evaluation of the Popularization Method of MOOC Video Production. Modern Distance Education Research, No. 1, 106-112.

Zheng, J., Zhao, H., Yan, Z., Wang, F., Ma, Z., \& Zhang, H. (2012). The Role of Teachers in Multimedia Video Learning. Psychological Research, No. 5, 85-90.

Zheng, W. (2014). Emotional Design of Micro-Classes: Concept, Connotation, Model and Strategy. China Audio-Visual Education, No. 6, 101-106. 